\title{
Psychometric properties of the WHOQOL-BREF(PT) in a sample of elderly citizens
}

\author{
Margarida Goes ${ }^{1,2}$, Manuel Lopes ${ }^{2}$, João Marôco ${ }^{3}$, Henrique Oliveira $^{1,4^{*}}$ (i) and César Fonseca ${ }^{2}$
}

\begin{abstract}
Background: The goal of this article was to research the psychometric properties of the WHOQOL-BREF(PT) instrument in a sample of elderly citizens residing in a rural area in their own homes or at family members' or friends' homes and to compare the results: (i) to those reported by the team of Portuguese researchers that undertaken the instrument's translation/validation to the Portuguese language and (ii) to those reported internationally by the World Health Organization Quality of Life group. An overall quality of life scoring ( $\mathrm{QOL}_{24}$-all facets) is also proposed in this article as novelty. The correlation level between $\mathrm{QOL}_{24}$ and the instrument's general facet was also investigated.
\end{abstract}

Methods: This was a cross-sectional study with a sample of 351 elderly citizens ( $46.4 \%$ males and $53.6 \%$ females) randomly selected from the official dataset of the Local Health Unit of Baixo Alentejo. All the data were collected by health professionals at the participants' homes following the structured interview methodology and using the WHOQOL-BREF(PT) instrument. Three different structural equation models were developed: (i) a first-order confirmatory factor analysis, to assess the instrument's psychometric properties; (ii) a hierarchical second-order confirmatory factor analysis model, to allow determining the $\mathrm{QOL}_{24}$ scoring; and (iii) a more generic structural equation model, to investigate the correlation level between $\mathrm{QOL}_{24}$ and the instrument's general facet.

Results: The WHOQOL-BREF(PT) showed an "almost very good" goodness of fit (comparative fit index of 0.949 and Tucker-Lewis index of 0.943), an adequate internal consistency (Cronbach's alpha: from 0.64 to 0.90; composite reliability: from 0.59 to 0.88 ) and tolerable convergent validity (average variance extracted: from 0.374 to 0.614 ). However, discriminant validity was not reached because strong correlations between the first-order factors (four QOL domains) were obtained, together with low values of the average variance extracted. The scoring of $\mathrm{QOL}$ domains and $\mathrm{QOL}_{24}$, determined as weighted averages (proposed in this article as novelty) were significantly different than those determined as unweighted averages. The standardized correlation coefficient between $\mathrm{QOL}_{24}$ and the instrument's general facet was of 0.89 (statistically highly significant).

Conclusions: The WHOQOL-BREF(PT) is a psychometrically sound instrument to assess the QOL of the considered population sample. However, the QOL domains were found strongly intertwined. More studies are necessary to validate the weighted average scoring strategy of $\mathrm{QOL}$ domains and $\mathrm{QOL}_{24}$. Concurrent validity between $\mathrm{QOL}_{24}$ and the instrument's general facet was considered as "strong".

Keywords: Elderly, Quality of life, WHOQOL-BREF, Psychometric properties, Structural equation modelling

\footnotetext{
*Correspondence: hjmo@|x.it.pt
}

${ }^{4}$ Instituto de Telecomunicações (IT), Lisbon, Portugal

Full list of author information is available at the end of the article original author(s) and the source, provide a link to the Creative Commons licence, and indicate if changes were made. The images or other third party material in this article are included in the article's Creative Commons licence, unless indicated otherwise in a credit line to the material. If material is not included in the article's Creative Commons licence and your intended use is not permitted by statutory regulation or exceeds the permitted use, you will need to obtain permission directly from the copyright holder. To view a copy of this licence, visit http://creativecommons.org/licenses/by/4.0/. The Creative Commons Public Domain Dedication waiver (http://creativeco mmons.org/publicdomain/zero/1.0/) applies to the data made available in this article, unless otherwise stated in a credit line to the data. 


\section{Background}

Organizations and institutions worldwide, as well as the latest scientific research, have shown an increase in individuals' average life expectancy, which is one of the features that has been used to explain the phenomenon of population aging $[1,2]$. However, the additional years of life gained come with a higher incidence/prevalence of noncommunicable diseases (multiple and complex comorbidities) and disabilities [3, 4], reflected in the increase in populations' disease burden [5], mainly in older age groups $[6,7]$. Consequently, a greater demand in managing age-related health conditions has been widely emphasized, mainly through the implementation of skilled healthcare services [8].

Even so, the major goal in the delivery of effective health care to patients with comorbidities and disabilities consists of reducing the impact of their illnesses, not only in terms of physical functioning but also on the different dimensions of their life [9]. But the uncertainty about disease diagnosis and prognosis, disease progression and the treatments that need to be delivered are aspects that, inevitably, may cause some degree of emotional disturbance that can affect individuals' life. Such emotional disturbance may result in significant changes in individuals' daily routines, namely: (i) interfering with their ability to work; (ii) compromising their family/social roles; and (iii) hindering their involvement in leisure activities [10]. Therefore, it is important to understand whether health care delivery provides "value" for the patients themselves [11], as well as to realize patients' concerns, hopes and expectations, rather than reducing their deficiencies and disabilities adopting only a biological and functional perspective $[4,12]$. This approach has motivated researchers and organizations worldwide to understand how comorbidities truly affect individuals' life, mainly in older age groups, and how these individuals self-report their disease burden [13].

Based on the above, an assessment that is capable of capturing the dynamic interaction between the individuals' external living conditions and their internal perception of these conditions has been progressively claimed $[14,15]$. This is one of the main reasons why measuring individuals' quality of life (QOL) is becoming increasingly popular, with the aim of capturing individuals' perception of their own health and their hopes, expectations and feelings after the delivery of health care $[12,16]$. Additionally, QOL assessment has also been considered an important outcome of healthcare delivering in different clinical scenarios [17]. Therefore, identifying why individuals have poor QOL may help to ensure adequate health personnel for treatment and rehabilitation interventions, with the aim of improving individuals' physical and mental health, level of independence, social relations, personal convictions and beliefs. On the other hand, QOL assessment may favor the implementation of well-informed public health policies, which may contribute to the avoidance of acute health scenarios in terms of older individuals' diseases and disabilities [15]. In short, QOL assessment may lead to the promotion of an healthy life and populations' well-being, especially among older individuals, who represent the population group that reports the greatest burden of noncommunicable diseases $[7,16]$.

The strong worldwide interest in measuring QOL led the World Health Organization (WHO), through the World Health Organization Quality of Life (WHOQOL) group, to develop the most comprehensive concept of QOL found in the scientific literature, favoring a transcultural, multidimensional and a subjective view of this construct [18]. To enable a QOL measurement, two instruments of international scope were developed by the WHOQOL group [19] in collaboration with several institutional groups worldwide: (i) the WHOQOL-100, which comprises 24 facets on QOL (four items per each facet) and one general facet (four items) [20] and (ii) the WHOQOL-BREF, which comprises the same 24 facets as in the former instrument, but only one item per each facet, and one general facet - GF (two items) [21]. The WHOQOLBREF is considered the abbreviated version of the first instrument $[22,23]$.

A group of Portuguese (European) researchers, in collaboration with the WHOQOL group, accomplished the translation and validation of both international versions of the instruments in the Portuguese language between early 2004 and 2006, to allow others to research the QOL of Portuguese citizens using the WHOQOL instruments [19]. Similar translation/validation work was also performed in many cultures and languages [22, 23]. As a result of the important work conducted by the aforementioned group of Portuguese researchers, the following Portuguese (PT) versions of both international instruments were published: the WHOQOL-100(PT) [24] and the WHOQOLBREF(PT) [25]. These versions have the same factorial models as the corresponding international versions, with the latter being the instrument under discussion in this article. During the translation/validation of the WHOQOL-BREF international instrument in the Portuguese language, the aforementioned group of Portuguese researchers collected data from two samples from a younger-adult population, in accordance with the standards issued by the WHOQOL group for the sample composition: (i) the "healthy group" (the average age was 40 years old) and (ii) the "clinical group" (comprising 50\% of individuals aged equal to or greater than 45 years old), with this latter group composed of 
individuals who had health conditions and who were registered in three public health units of Coimbra city in different medical specialties [26].

However, reliability and validity are not fixed properties of a scale [27]. For example, as stated by Keszei et al. [28, page 321], "It is wrong to talk about the reliability of a scale, as opposed to the reliability of a scale used with a specific population for a given purpose., and "A scale that is reliable in one set of circumstances may not be reliable under different conditions.. Based on this, the psychometric properties of the WHOQOL-BREF(PT) were reevaluated in a sample of elderly citizens (individuals with higher burden of noncommunicable diseases, mostly unemployed and retired) residing in a rural area (substantial proportion of illiterates, living in a region with a scarce transportation network that difficult the access to healthcare services), rather than in a sample of a youngeradult population living in a major city, to assess the psychometric soundness of the instrument [29]. Moreover, a comparison of the psychometric properties of the WHOQOL-BREF(PT) obtained in this article to those attained by the aforementioned group of Portuguese researchers [26] and those reported in Skevington et al. [23] was also undertaken, to ascertain how different or similar these properties might be.

Since QOL is a multidimensional construct, comprising several dimensions of individuals' life, some authors have found that it may be important to summarize this construct, instead of reporting the findings of QOL domains separately, as it may allow for a cohesive picture of QOL [30]. As this topic was not considered during the translation/validation of the WHOQOL-BREF international version in the Portuguese language, or even by the WHOQOL group, a strategy to determine an overall QOL scoring, here designated as $\mathrm{QOL}_{24}$ and comprising the 24 facets on QOL, is proposed in this article as novelty.

In short, the novel contributions of this article, specifically those related to the work previously undertaken by the group of Portuguese researchers on QOL [26], are listed as follows: (i) to re-evaluate the psychometric properties of the WHOQOL-BREF(PT) in a sample of elderly citizens, namely: the goodness of fit, scale's internal consistency, convergent and discriminant validity, through a first-order confirmatory factor analysis (first-order CFA); (ii) to determine the $\mathrm{QOL}_{24}$ scoring, through a hierarchical second-order confirmatory factor analysis (H-secondorder CFA); and (iii) to infer about the correlation level between the $\mathrm{QOL}_{24}$ and GF latent variables (latent factors), through a more generic structural equation modeling (SEM). All the research work was carried out using a sample of elderly citizens (more than or equal to 65 years old) residing in the community, in their own homes or at family members' or friends' homes.

\section{Methods \\ Ethical considerations}

The Health Ethics Committee of the Local Health Unit of Baixo Alentejo (HECLHUBA) [31] approved the study protocol on July 6 th, 2014. The decision was published in the minutes of meeting issued by the HECLHUBA board of directors, with the reference number $2 / 2014$. The HECLHUBA also approved the study design, methods, interview procedures and the informed consent form to be presented to each participant. Moreover, all the research methods were performed in full accordance with the statements included in the operating regulations of HECLHUBA [32], a document that was developed in accordance with the Helsinki Declaration with the aim of protecting the dignity, privacy and freedom of the participants [33].

\section{Study area}

The Baixo Alentejo (BA) region [34] was chosen for this research because: (i) it presents a complex, worrisome and heterogeneous sociodemographic situation in regard to population aging; (ii) it has a significant rural context since it is located in the south-central area of mainland Portugal; (iii) it has a very low population density, with geographic distances between villages ranging from 25 to $120 \mathrm{~km}$; and (iv) it has a limited and insufficient public transportation network, causing serious difficulties in terms of the displacement of elderly citizens living on their own means.

\section{Sample size}

This research involved older individuals (more than or equal to 65 years old) who were residing in their own homes or at family members' or friends' homes. All the participants were registered in the database of the Local Health Unit of Baixo Alentejo (LHUBA), comprising 32,893 elderly citizens [35].

To determine the appropriate sample size $n$ and the stratum sample sizes $n_{1}$ to $n_{6}$ (by gender - male and female - and by age group - 65 to 74,75 to 84 , and 85 years or older), the formulae proposed by Scheaffer et al. [36, page 128] were adopted. More precisely, the equation (5.10) was used to determine the sample size $n$, while the equation (5.9) - called the Neyman allocationwas employed to obtain $n_{1}$ to $n_{6}$. Additionally, the stratum standard deviations were calculated as $\sqrt{\pi_{i} \times\left(1-\pi_{i}\right)}$, see Oliveira [37 pp. 65-66], where $\pi_{i}$ denotes the population proportion of the $i$ th stratum, set as 0.5 in this article since it represents the worst scenario in terms of $n$. Moreover, the sample size $n$ was determined with a 
bound on the error of estimation equal to $4.5 \%$ (empirically chosen). Finally, the calculated sample size was 468 individuals. However, the final sample totaled 351 older individuals (163 males and 188 females who were randomly selected from the entire LHUBA database) who signed the informed consent form and answered the instrument fully and correctly (with no missing data).

According to the "Calculator: a priori Sample Size for Structural Equation Models" [38, 39], for an anticipated effect size of 0.3 (a medium effect, based on Cohen [40]), a desired statistical power level of 0.8 (a reasonable value as stated by Westland [41]), 4 latent variables (latent factors) and 24 instrument items (the 2 items belonging to the GF were not included in this calculation because they did not belong to the first-order and $\mathrm{H}$-second-order CFA models), as well as a $p$-value of $5 \%$ [41], the a priori minimum sample size is 200 (even if a desired statistical power level of 0.9 is adopted, the resulting calculation remains unchanged).

The age of the respondents ranged from 65 to 101 years old. The average age and standard deviation were of 78.1 and 7.86 , respectively.

\section{Inclusion criteria}

The adopted inclusion criteria were as follows: individuals who (i) were aged 65 or older; (ii) were interested in participating in the study; (iii) were residing in BA region in their own homes or at family members' or friends' homes; and (iv) were able to make their own decisions if they were sick or were hospitalized due to acute, shortterm health care needs.

\section{Data collection}

Data were collected between January 2016 and April 2017 at the elderly citizens' homes or their family members' or friends' homes by teams of health professionals from LHUBA. A structured interview methodology was adopted using the WHOQOL-BREF(PT) instrument [25]. All health professionals from LHUBA involved in the study received prior training on how to conduct the interviews, how to provide all necessary clarifications regarding the content of the instrument used, and how to avoid missing data. Before each interview, each health professional provided an informed consent form to the respondent or his/her family. Information on the study objectives was provided in full to the respondents and/or their families, and they were informed of the confidentiality and anonymity of the data.

\section{Instrument}

The WHOQOL-BREF(PT) instrument comprises 24 facets (one item per each facet) clustered into four domains [25]: (i) Physical Health (7 facets), (ii) Psychological (6 facets), (iii) Social Relationships (3 facets), and (iv) Environment (8 facets). Additionally, it also includes a GF, which comprises 2 items of a general nature: (i) first, an item asking how the respondent would rate his/her quality of life (labeled as "overall QOL" in Skevington et al. [23] and G1 in this article), and (ii) second, an item asking how the respondent would rate his/her satisfaction with his/her health (labeled as "overall health" in Skevington et al. [23] and G4 in this article). All WHOQOL$\operatorname{BREF}(\mathrm{PT})$ facets are measured using a five-point Likert scale (1 to 5), with the F1.4, F11.3 and F8.1 measured on an inverted scale. A list of all the facets is included in the appendix. The main characteristics of the WHOQOL-BREF(PT) instrument are as follows [21]: (i) it is cross-cultural; (ii) it can be applied to individuals living in different contexts; (iii) it is capable of capturing individuals' own views of their well-being; and (iv) it should be self-administered if participants reveal enough reading skills.

\section{Statistical procedures}

The goodness of fit, scale's internal consistency, convergent and discriminant validity were assessed by employing a first-order CFA model (neither developed by Canavarro et al. [26] nor by Skevington et al. [23]) rather than the calculation of Pearson's correlation coefficients between QOL domains, using the lavaan package of version 0.6-6 [42] for R statistics software of version 4.0.2 [43]. The diagonally weighted least squares (DWLS), specifically designed when neither the normality assumption nor the continuity property is considered plausible, was the estimator of the model parameters employed in the lavaan package for ordinal data [44], in which the diagonal weight matrix is used instead of the full weight matrix [45].

The goodness of fit was evaluated using the following fit indexes: (i) comparative fit index (CFI); (ii) TuckerLewis index (TLI); (iii) root mean square error of approximation (RMSEA); (iv) 90 percent confidence interval for the population RMSEA (RMSEA $\mathrm{CI}_{(90 \%)}$ ); and (v) test of the null hypothesis that the population RMSEA would be no greater than 0.05 , often referred as PClose. The scale's internal consistency was evaluated with Cronbach's alpha coefficients (usually $\alpha_{c}^{j}>0.6$ for the $j$ th latent factor) and an alternative measure, i.e., the composite reliability $(\mathrm{CR})$, calculated using the standardized factor loadings $\left(\lambda_{\mathrm{ij}}\right)$ of the $i$ th reflective items of $j$ th latent factor (usually $C_{\mathrm{j}} \geq 0.7$, as recommended by Marôco [46, page 183]). Convergent validity was evaluated by the average variance extracted (AVE) of each latent factor (usually $\mathrm{AVE}_{\mathrm{j}} \geq 0.5$, again as recommended by Marôco [46, page 184]). Finally, the discriminant validity was assessed based on the positive validity of the expression 
$\left[\left(\sqrt{A V E_{l}}>\rho_{l k}\right) \wedge\left(\sqrt{A V E_{k}}>\rho_{l k}\right)\right]$, where $l k$ represents the $l$ th and $k$ th latent factors and $\rho_{l k}$ is their standardized correlation coefficient [46].

A H-second-order CFA was implemented as in Skevington et al. [23] (not developed by Canavarro et al. [26]), to determine the score of $\mathrm{QOL}_{24}$ latent factor. The correlation level between $\mathrm{QOL}_{24}$ and GF latent variables was assessed trough a more generic SEM (designated in this article as $\mathrm{SEM}_{\mathrm{QOL}_{24}-\mathrm{GF}}$ ) rather than a multilinear regression analysis (with the QOL domains as the endogenous variables and GF as the exogenous variable) as in Canavarro et al. [26]. The goodness of fit of both the $\mathrm{H}$-second-order CFA and $\mathrm{SEM}_{\mathrm{QOL}_{24}-\mathrm{GF}}$ models was evaluated using the same fit indexes previously mentioned for the first-order CFA. The scoring of the four QOL domains and $\mathrm{QOL}_{24}$ was performed based on the factor score weights $\left(f_{s} w_{i}\right)$ - one per item - predicted from the $\mathrm{H}$-second-order CFA model, resulting in weighted averages,

Table 1 Results of the sample size allocation procedure

\begin{tabular}{lccccc}
\hline Variables & \multicolumn{2}{c}{ Calculated } & & \multicolumn{2}{c}{ Participants } \\
\cline { 2 - 3 } & $\mathbf{n}$ & \% & & $\mathbf{n}$ & $\%$ \\
\hline Male & 195 & 41.7 & & 163 & 46.4 \\
$65-74$ & 93 & 47.7 & 64 & 39.3 \\
$75-84$ & 77 & 39.5 & 58 & 35.6 \\
85 or more & 25 & 12.8 & 41 & 25.1 \\
Female & 273 & 58.3 & 188 & 53.6 \\
65-74 & 111 & 40.7 & 68 & 36.2 \\
75-84 & 111 & 40.7 & 77 & 40.9 \\
85 or more & 51 & 18.6 & 43 & 22.9 \\
\hline
\end{tabular}

where the $f s w_{i}$ values were used as weights after their standardization to $100 \%$.

Nonparametric tests of the means (paired samples) were also conducted to compare the sample scores for the QOL domains calculated through the two different strategies: (i) unweighted average, as in Canavarro et al. [26] and Skevington et al. [23], and (ii) weighted averages, as proposed in this article as novelty.

\section{Results}

\section{Sample size allocation}

Table 1 lists the results of the sample size allocation procedure for the "calculated" sample size and the real number of "participants". Following Westland [41], who stated that "for non-normal data such as Likert scale data, sample sizes of at least one to two magnitudes larger may be needed", the number of 351 participants involved in this research work was in accordance with the author's statement because it was approximately $175.5 \%$ more than 200 (see the penultimate paragraph of Sample size subsection).

\section{First-order CFA}

The overall fit of the first-order CFA model (see the model in Fig. 1) was classified as "almost very good" (see Table 2). The standardized factor loadings $\left(\lambda_{\mathrm{i}}\right)$ were $0.38 \leq \lambda_{\mathrm{i}} \leq 0.98$ (see Fig. 1, all were statistically highly significant, $p<0.001$ ), with an average of 0.69 , and only one $\lambda_{\mathrm{i}}$ below the threshold value of $0.5\left(\lambda_{\mathrm{F} 19.3}=0.38\right)$. For the assessment of the scale's internal consistency (see Table 3) based on the $\alpha_{c}^{j}$ measure (see Table 3), all domains presented values above the admissible threshold of 0.6. However, considering the reliability analysis based on the CR measure, only the Social

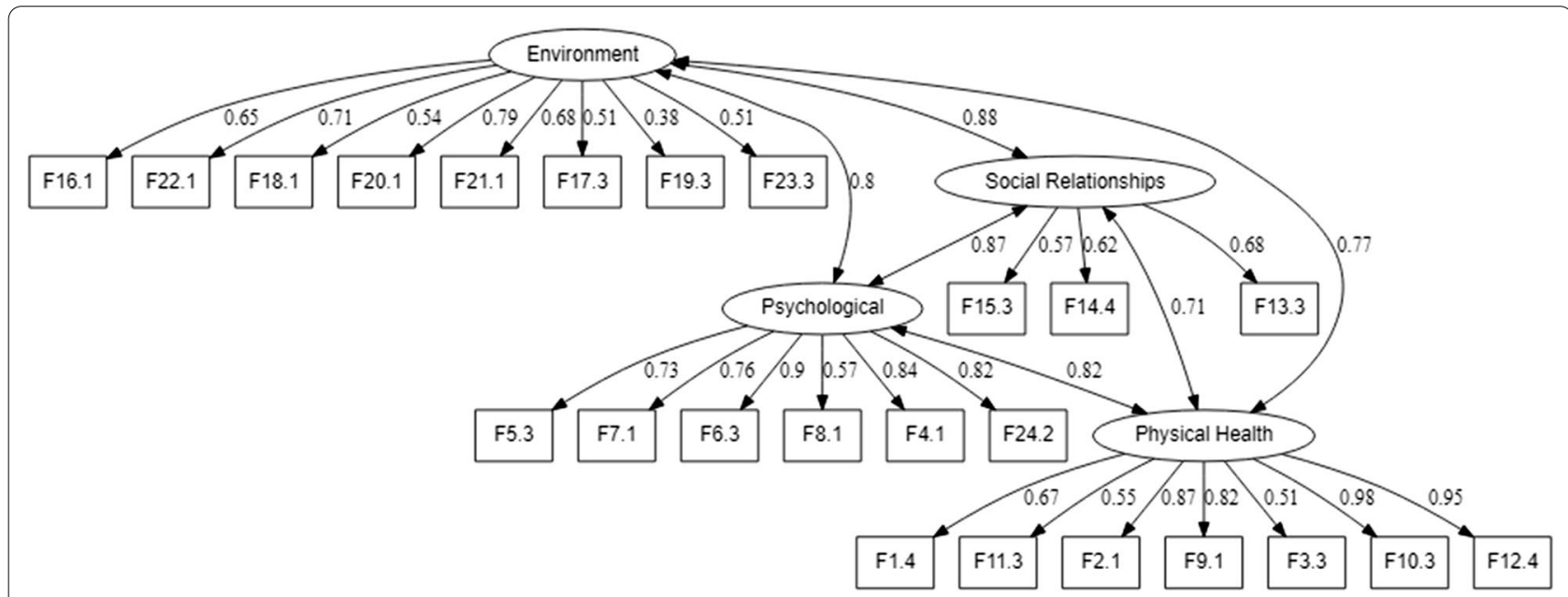

Fig. 1 First-order CFA model of the WHOQOL-BREF(PT) 
Relationships domain presented a value lower than 0.7 (this index was not available neither in Canavarro et al. [26] nor in Skevington et al. [23]). With respect to the convergent validity (see Table 3), the Physical Health and Psychological domains presented values above the recommended threshold of 0.5 , although values of $0.3 \leq \mathrm{AVE}_{\mathrm{j}}<0.5$ may be considered "acceptable" in the case of exploratory research [46, p. 184] (this index was not available neither in Canavarro et al. [26] nor in Skevington et al. [23]). The first-order CFA model presented no discriminant validity since the results of all possible expressions $\left[\left(\sqrt{A V E_{l}}>\rho_{l k}\right) \wedge\left(\sqrt{A V E_{k}}>\rho_{l k}\right)\right]$ were "false". Regarding the standardized correlation coefficients between the QOL domains $\left(\rho_{l k}\right)$, all were statistically highly significant $(p<0.001$, see Table 3$)$.

\section{H-second-order CFA}

A $\mathrm{H}$-second-order CFA model was developed as in Skevington et al. [23], by positioning a higher-order factor, called $\mathrm{QOL}_{24}$, as shown in Fig. 2. As suggested by the values in Table 2, the $\mathrm{H}$-second-order CFA also showed an "almost very good" fit, with the $\mathrm{QOL}_{24}$ latent

Table 2 Results of the robust solution regarding the three SEM models

\begin{tabular}{lllll}
\hline Indexes & \multicolumn{2}{l}{ Index values } & & Qualitative classification $^{\text {a }}$ \\
\cline { 2 - 4 } & First-order CFA & H-second-order CFA & SEM $_{\mathrm{QOL}_{24}-\mathrm{GF}}$ & \\
\hline$X^{2}$ & 1022.622 & 1042.076 & 1131.384 & - \\
$\mathrm{df}$ & 246 & 248 & 294 & - \\
$p$ value $\left(X^{2}\right)$ & $<0.001$ & $<0.001$ & $<0.001$ & - \\
$\mathrm{CFI}$ & 0.949 & 0.948 & 0.949 & Almost very good \\
$\mathrm{TLI}$ & 0.943 & 0.942 & 0.943 & Almost very good \\
RMSEA & 0.095 & 0.096 & 0.090 & Admissible \\
RMSEA $_{\mathrm{Cl}(90 \%)}$ & {$[0.089 ; 0.101]$} & {$[0.090 ; 0.102]$} & {$[0.085 ; 0.096]$} & - \\
PClose & $<0.001$ & $<0.001$ & $<0.001$ & - \\
\hline
\end{tabular}

${ }^{\text {a According to Marôco [46] }}$

Table 3 Measures of internal consistency (CR and $\alpha_{c}^{j}$ ), AVE and correlation coefficients between the QOL domains (values reported in Canavarro et al. [26] are shown in square brackets, while the ones reported in Skevington et al. [23] are shown in round brackets, if available)

\begin{tabular}{|c|c|c|c|c|}
\hline & Physical health & Psychological & Social relationships & Environment \\
\hline$\alpha_{C}^{j}$ & $\begin{array}{l}0.90 \\
{[0.87]} \\
(0.82)\end{array}$ & $\begin{array}{l}0.89 \\
{[0.84]} \\
(0.81)\end{array}$ & $\begin{array}{l}0.64 \\
{[0.64]} \\
(0.68)\end{array}$ & $\begin{array}{l}0.81 \\
{[0.78]} \\
(0.80)\end{array}$ \\
\hline$C R_{j}$ & 0.88 & 0.86 & 0.59 & 0.78 \\
\hline $\operatorname{AVE}_{j}$ & 0.614 & 0.606 & 0.390 & 0.374 \\
\hline Physical health & 1.00 & - & - & - \\
\hline Psychological & $0.82^{* *}\left[0.55^{* *}\right]^{\mathrm{a}}$ & 1.00 & - & - \\
\hline Social relationships & $0.71^{* *}\left[0.56^{* *}\right]^{\mathrm{a}}$ & $0.87^{* *}\left[0.72^{* *}\right]^{\mathrm{a}}$ & 1.00 & - \\
\hline Environment & $0.77^{* *}\left[0.57^{* *}\right]^{\mathrm{a}}$ & $0.80^{* *}$ & $0.88^{* *}$ & 1.00 \\
\hline
\end{tabular}

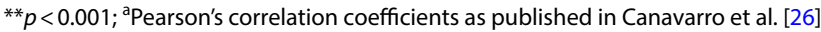

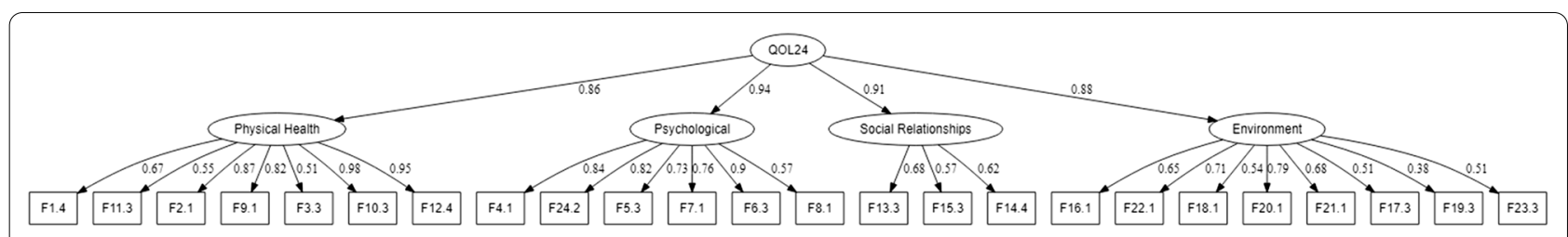

Fig. $2 \mathrm{H}$-second-order CFA model of the WHOQOL-BREF(PT) 
factor operationalized by four latent variables (Physical Health, Psychological, Social Relationships and Environment), in which each of the four latent variables was operationalized by several observed variables (comprising the 24 facets of the instrument). Regarding the standardized factor loadings $\left(\lambda_{\mathrm{i}}\right)$, the ones reported in Skevington et al. [23] (shown in round brackets) were somewhat similar to those obtained within this article, i.e., $0.38(0.40) \leq \lambda_{i} \leq 0.98(0.82)$, see Fig. 2. With respect to the correlations between $\mathrm{QOL}_{24}$ and the four domains (designated in this article as $\rho_{j}$ ), all were strong and statistically highly significant $(p<0.001)$, and slightly higher than those reported in Skevington et al. [23] (shown in round brackets): (i) $\rho_{\text {Physical Health }}=0.86(0.87)$; (ii) $\rho_{\text {Psycho }}$ logical $_{1}=0.94(0.95)$; (iii) $\rho_{\text {Social Relationships }}=0.91(0.83)$ and (iv) $\rho_{\text {Environment }}=0.88(0.84)$, see Fig. 2 . The $\mathrm{CR}_{\mathrm{QOL}_{24}}$ and $\alpha_{c} \mathrm{QOL}_{24}$ measures showed very good values, respectively 0.943 and $0.940\left(\alpha_{c}^{Q O L_{24}}=0.92\right.$, reported only in Canavarro et al. [26]). Finally, $\mathrm{AVE}_{\mathrm{QOL}_{24}}=0.807$, which was above the admissible threshold of 0.5 (not reported neither in Canavarro et al. [26] nor in Skevington et al. [23]).

$$
\mathrm{SEM}_{\mathrm{QOL}_{24}-\mathrm{GHF}}
$$

Regarding the standardized factor loadings $\left(\lambda_{\mathrm{i}}\right)$, the values were $0.38 \leq \lambda_{\mathrm{i}} \leq 0.98$ (all were statistically highly significant, $p<0.001$ ), with an average of 0.69 , and only one $\lambda_{i}$ was below the threshold value of $0.5\left(\lambda_{F 19.3}=0.38\right)$. As described in the "Methods" section, the WHOQOLBREF(PT) includes a GF comprising two items (G1 and G4). A third SEM model (see Fig. 3) was developed to investigate the correlational level between the $\mathrm{QOL}_{24}$ and GF latent factors. The fit indexes for this model were very similar to those of the previous two CFA models, as listed in Table 2, also classified qualitatively as "almost very good". The correlation level between $\mathrm{QOL}_{24}$ and GF was strong $(\rho=0.89 ; p<0.001)$.

\section{Descriptive statistics}

Table 4 summarizes the descriptive statistics regarding the four QOL domains, $\mathrm{QOL}_{24}$ and GF, while Fig. 4 shows the results of the average scoring obtained from two different strategies: unweighted average (black bars) and the use of the $f s w_{i}$ (weights in the weight average strategy) predicted from the $\mathrm{H}$-second-order CFA model (bars depicted in light gray). The results of nonparametric tests (paired data) seem to suggest that the differences found in the scores of each of the four QOL domains and the $\mathrm{QOL}_{24}$ (between the unweighted and weighted averages) were not due to chance, because each difference was statiscally highly significant $(p<0.001)$. However, no evidence was found to support the rejection of the null hypothesis in relation to the GF factor regarding this topic.

\section{Discussion}

The first objective proposed in this article was to assess the goodness of fit, internal consistency, convergent and discriminant validity of the WHOQOL-BREF(PT) based on a first-order CFA model (see Fig. 1), which is considered an appropriate strategy if a factorial model is already available [47]. The findings reported in the previous section seem to suggest that the WHOQOL$\mathrm{BREF}(\mathrm{PT})$ instrument showed an "almost very good" goodness of fit. All the standardized factor loadings were above the threshold of 0.3 , as recommended by

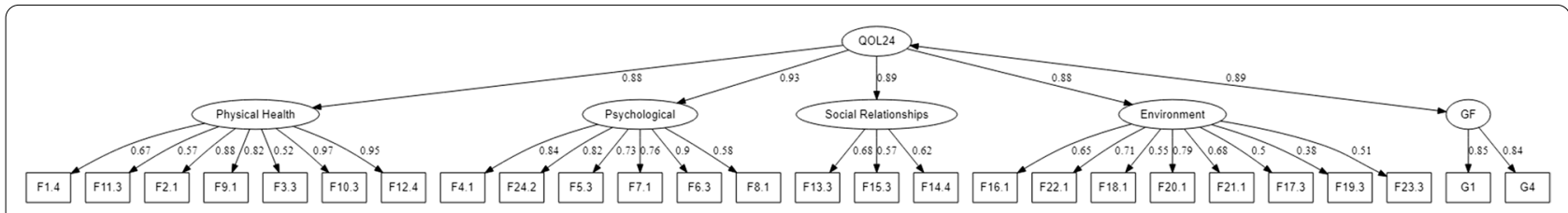

Fig. 3 SEM QOL $_{24}-$ GF model of the WHOQOL-BREF(PT)

Table 4 Descriptive statistics of the latent factors of the WHOQOL-BREF(PT)

\begin{tabular}{llllllllll}
\hline Domains & Mean & Median & SD & Skewness & SE $_{\mathbf{S k}}$ & Kurtosis & SE $_{\mathbf{K u}}$ & Min & $\mathbf{M a x}$ \\
\hline Physical health & 3.254 & 3 & 1.042 & -0.118 & 0.049 & -0.823 & 0.099 & 1 & 5 \\
Psychological & 3.392 & 4 & 0.901 & -0.367 & 0.053 & -0.296 & 0.107 & 1 & 5 \\
Social relationships & 3.439 & 4 & 0.842 & -0.444 & 0.075 & 0.184 & 0.151 & 1 & 5 \\
Environment & 3.365 & 4 & 0.929 & -0.538 & 0.046 & -0.188 & 0.092 & 1 & 5 \\
QOL $_{24}$ & 3.348 & 3 & 0.948 & -0.361 & 0.027 & -0.412 & 0.053 & 1 & 5 \\
GF & 3.056 & 3 & 0.927 & -0.154 & 0.092 & -0.607 & 0.184 & 1 & 5 \\
\hline
\end{tabular}




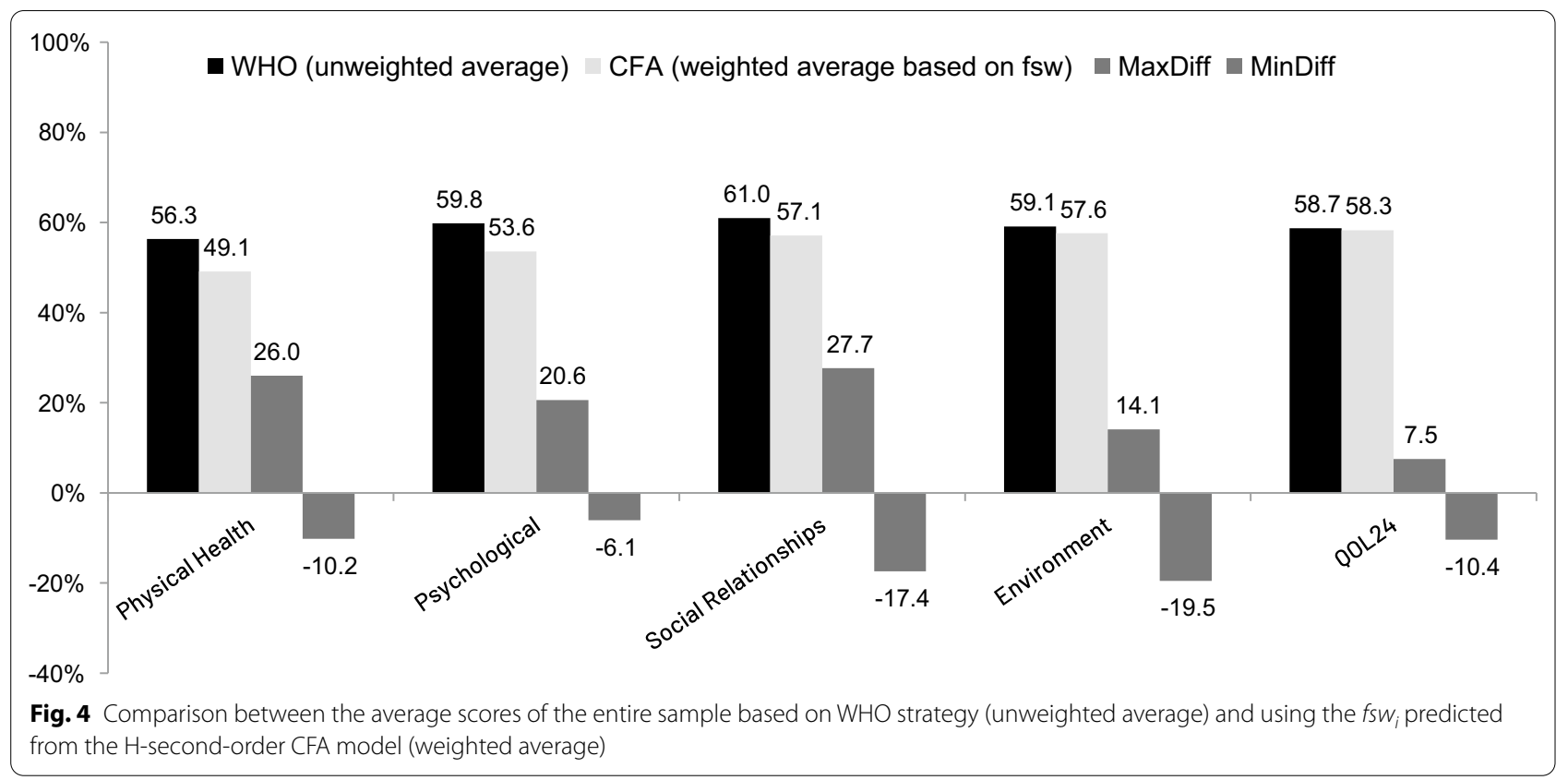

Fleck [14]. An adequate internal consistency (similarly reported in Canavarro et al. [26] and Skevington et al. [23]) was also reached. Regarding the lower value of $\alpha_{c}$ Social Relationships, researchers usually explain such a finding to be a result of the small number of items included within this QOL domain $[14,18,26]$, which is in line with the fact that this metric is affected by the number of items in a latent factor $[23,46]$. The reported results also seem to suggest that a tolerable convergent validity was achieved. Strong correlations between first-order factors (higher than those reported in Canavarro et al. [26], see Table 3) and lower AVE values were obtained. Since the $\mathrm{AVE}_{\mathrm{j}}$ values were less than the square of the correlation between the latent factors involved, the instrument did not show discriminant validity. While the discriminant validity based on CFA follows the Fornell-Larcker criterion [47], Canavarro et al. [26] adopted the strategy proposed by Nunnally and Bernstein [46]. However, because the Fornell-Larcker criterion is based on the correlations between QOL domains, it can help infer the extent to which the domains are related to each other [30]; i.e., (i) strong correlations among domains may suggest that changes in a domain can have significant impacts on other domains, while (ii) weak correlation among domains may suggest that changes in one domain can have little or no impact on other domains. Considering this inference and the strong correlations between first-order latent factors, it is possible to establish a relationship between the findings obtained within the scope of this article and the results reported by Van Leeuwen et al. [15, page 34], who stated: "However, it is important that service providers and care professionals realize that the QoL domains are strongly intertwined, meaning that changes in one domain likely affect other QoL domains.". An additional comment is made regarding the discriminant validity achieved by Canavarro et al. [26] and Skevington et al. [23]. The authors evaluated a successful discriminant validity in their research work, such as the instrument's ability to differentiate individuals belonging to the "healthy" or "clinical" (patients) groups, based on the results of a Student's $t$-test used to compare the average scores of the QOL domains between the two groups. Therefore, it is difficult to compare the two results, those reached by Canavarro et al. [26] and Skevington et al. [23] and the ones achieved within the scope of this research work, since they were obtained based on different statistical methodologies.

The H-second-order CFA (see Fig. 2), which was more related to the research carried out by Skevington et al. [23] (not reported in Canavarro et al. [26]) and aimed to predict the $\mathrm{QOL}_{24}$ scoring, was also undertaken. The results of fit indexes seem to suggest that the proposed model adequately fit the sample data of elderly citizens residing in a rural area, suggesting that WHOQOL$\mathrm{BREF}(\mathrm{PT})$ may be considered a psychometrically sound instrument to assess the QOL of this population group [29]. Since the results in Skevington et al. [23] were presented in terms of four different samples (two split-half samples of the data, as well as the "sick persons" and "well persons" sub-samples), it is difficult to compare the fit indexes achieved by the authors with the ones obtained within the scope of this research work. Regarding the 
correlations between the $\mathrm{QOL}_{24}$ latent variable and each domain, the correlations presented in the $\mathrm{H}$-second-order subsection of this article were slightly higher than those reported in Skevington et al. [23], especially for the Social Relationships domain, again suggesting that QOL among older respondents is a construct that strongly relates several dimensions of their life, even more than in other population group [16]. Adopting the Aristotle's statement: "the whole is not the same as the sum of its parts", it may be interesting to obtain the $\mathrm{QOL}_{24}$ scoring based on the entire set of QOL domains because they are strongly intertwined and may allow for a cohesive picture of this construct [30]. Therefore, a scoring strategy for the four domains and $\mathrm{QOL}_{24}$ is presented in this article as novelty by determining the scores as weighted averages and using the $f s w_{i}$ values as weights. With respect to the results of nonparametric tests (paired samples), used to compare the scoring strategies by unweighted and weighted averages, they seem to suggest that all the differences observed between the two scoring strategies of the four domains and $\mathrm{QOL}_{24}$ (see Fig. 4 for details) were not due to chance. Additionally, in the analysis of individual scores (for each respondent separately), differences were also observed (see the small positive and negative bars depicted in dark gray in Fig. 4). Although the differences between the two scoring strategies may be easily detected through the employment of nonparametric tests (paired samples), their evaluation in terms of how they really corresponded to the individuals' QOL assessments may not seem to be an easy task. In fact, deciding between the two types of scoring (e.g., $59 \%$ based on the unweighted average or $48 \%$ based on the weighted average through the use of $f s w_{i}$ values), i.e., deciding which is the strategy that truly corresponds to the individual's $\mathrm{QOL}_{24}$ scoring, probably is a task that can only be taken by a group of experts (e.g., including health professionals, people from the community, healthy individuals and individuals presenting comorbidities). This methodology could allow expert consensus to be reached about which is the best matched scoring: the scoring based on an unweighted average strategy or the scoring proposed in this research work as novelty. Although the use of an unweighted average can be advantageous since it results in an invariant scale's scoring [42, 47], the use of $f s w_{i}$ values can allow for certain peculiarities of the QOL domains, which were captured by the structural equation modeling, be reflected in the scoring [46].

The correlation between the $\mathrm{QOL}_{24}$ and GF latent variables, which was not reported in Skevington et al. [23], was investigated in this article using a more generic SEM (see Fig. 3 for details). However, this was a different strategy than the one reported in Canavarro et al. [25], where a multilinear regression analysis was undertaken by the authors (with the QOL domains as the endogenous variables and GF as the exogenous variable) to identify which domains were considered the best predictors of the GF. In their research work, the Physical Health domain was considered the best predictor of the GF, with a variance explained of 52.2\%, followed by the Psychological, Environment and Social Relationships domains, in descending order of the variance explained. Concerning the $\mathrm{SEM}_{\mathrm{QOL}_{24}-\mathrm{GF}}$ model undertaken in this article, the correlation between the $\mathrm{QOL}_{24}$ and GF latent variables was found to be quite strong, suggesting that the GF, which comprises the G1 and G4 items, may be a latent factor that can be used as a generalized measure of QOL. This finding indicates that concurrent validity between these two latent variables was reached, thus accomplishing the third objective of this research work. In addition to this finding, it is important to mention that the use of the GF factor (only 2 items) instead of the full set of 24 items may be considered, although with some caution (only if concurrent validity between $\mathrm{QOL}_{24}$ and GF latent factors is reached), especially in large clinical settings and epidemiological surveys, where the respondent burden must be minimized, or in cases where it is necessary to reduce the number of variables in a model [22, 23]. However, more studies must be undertaken to check the validity of using the GF as a generalized measure of $\mathrm{QOL}_{24}$.

\section{Conclusions}

This article presents a new perspective regarding the assessment of the WHOQOL-BREF(PT) psychometric properties based on SEM models and applying the instrument to elderly citizens residing in a rural area with a very low population density in mainland Portugal (Europe). The findings in this research seems to suggest that the WHOQOL-BREF(PT) is a psychometrically sound instrument that can be used to assess the QOL of the considered population sample, although discriminating validity could be a psychometric property that may be difficult to be reached. Summarizing the domain measures into the $\mathrm{QOL}_{24}$ scoring may give a cohesive picture of QOL, especially if strong correlations among domains are found, which was the case in this article, corroborating the finding that QOL is a construct that strongly involves several dimensions of older individuals' life. Concurrent validity between $\mathrm{QOL}_{24}$ and GF was also achieved, which may suggest that the GF can be used as a generalized QOL measure, although with some caution.

\section{Limitations and future research}

The number of respondents, which was lower than expected, was one of the weaknesses of this study, leading to a higher sample error than expected. Another limitation was related to the fact that this was not a longitudinal study, 
so long-term follow-up was not carried out; long-term follow-up is an important strategy that allows the examination of the instrument's sensitivity to capture changes in health states over time. Moreover, it was not possible to perform test-retest reliability and longitudinal time invariance tests. Since there are no reference values for "good" or "bad" QOL, it is therefore not possible to carry out a qualitative assessment of this construct. Given the usefulness of measuring this construct in clinical assessment, further research is recommended to create a normative basis to promote its construction. Furthermore, the weighted scoring of $\mathrm{QOL}_{24}$ should be validated by a group of experts (e.g., including health professionals, people from the community, healthy individuals and individuals presenting comorbidities) to reach expert consensus about this topic.

\section{Appendix}

\section{List of WHOQOL-BREF(PT) facets/items}

General facet:

G1. Overall quality of life

G4. Overall health

Physical Health domain:

F1.4 Pain and discomfort

F2.1 Energy and fatigue

F3.3 Sleep and rest

F9.1 Mobility

F10.3 Activities of daily living

F11.3 Dependence on medication or health care

F12.4 Work capacity

Psychological domain:

F4.1 Positive feelings

F5.3 Thinking, learning, memory and concentration

F6.3 Self-esteem

F7.1 Body image and appearance

F8.1 Negative feelings

F24.2 Spirituality/religion and personal beliefs

Social relationships domain:

F13.3 Personal relations

F14.4 Practical social support

F15.3 Sex

Environment domain:

F16.1 Physical safety and security

F17.3 Home environment

F18.1 Financial resources

F19.3 Health and social care: availability and quality

F20.1 Opportunities to acquire new information and skills

F21.1 Recreation and leisure

F22.1 Physical environment (pollution/noise/traffic/ climate)

F23.3 Transport

\section{Abbreviations}

AVE: Average variance extracted; BA: Baixo Alentejo (the study region); BD: Burden of disease; CFA: Confirmatory factor analysis; CFI: Comparative fit index; CHRC: Comprehensive Health Research Centre; CR: Composite reliability; DWLS: Diagonally weighted least squares; fsw: Factor score weight; GF: General facet; HECLHUBA: Health Ethics Committee of Local Health Unit of Baixo Alentejo; LHUBA: Local Health Unit of Baixo Alentejo; MI: Modification index; PClose: Test of the null hypothesis that the population RMSEA would be no greater than 0.05; QOL: Quality of life; RMSEA: Root mean square error of approximation; RMSEA $\mathrm{Cl}_{(90 \%)}$ : 90 Percent confidence interval for the population RMSEA; $\mathrm{SE}_{S \mathrm{Sk}}$ : Standard error of skewness; $\mathrm{SE}_{\mathrm{Ku}}$ : Standard error of kurtosis; SEM: Structural equation model; SD: Standard deviation; TLI:Tucker-Lewis index; WHO: World Health Organization; WHOQOL: World Health Organization Quality of Life; WHOQOL-100: The international version of the instrument issued by the World Health Organization (in the English language); WHOQOL100(PT): Version of the WHOQOL-100 instrument in the Portuguese language; WHOQOL-BREF: The international version of the instrument issued by the World Health Organization (in the English language); WHOQOL-BREF(PT): Version of the WHOQOL-BREF instrument in the Portuguese language.

\section{Acknowledgements}

The authors acknowledge the specialized support given by the health professionals from LHUBA (http://www.ulsba.min-saude.pt/) [accessed on December 25th, 2020], who collaborated on the data acquisition (home interviews). The authors also acknowledge the support given by Professor Diógenes Bido (diogenesbido@yahoo.com.br) from the Mackenzie Presbyterian University regarding the first steps on using the lavaan package for $\mathrm{R}$ statistics software.

\section{Authors' contributions}

MG conceived the study as part of her PhD studies in Nursing under the supervision of $\mathrm{ML}$ and $\mathrm{HO}$. JM and $\mathrm{HO}$ contributed to the development of all statistical analysis models for all data. MG and $\mathrm{HO}$ assumed full responsibility for the integrity of the data, while JM was the senior guarantor of the correctness of the statistical analysis models. $\mathrm{HO}$ and CF were the guarantors of all the data. All authors have read and approved the final manuscript.

\section{Authors' Information}

Margarida Goes is a researcher at the Comprehensive Health Research Centre (CHRC) and an Adjunct Professor at the Health School of the Polytechnic Institute of Beja.

Manuel Lopes is a researcher at the CHRC and an Associate Professor at the Nursing School of the University of Évora.

Henrique Oliveira is a researcher at the Instituto de Telecomunicações (IT) and an Associate Professor at the School of Technology and Management of the Polytechnic Institute of Beja.

César Fonseca is a researcher at the CHRC and an Adjunct Professor at the Nursing School of the University of Évora.

\section{Funding}

The present publication was funded by Fundação Ciência e Tecnologia, IP national support through CHRC (UIDP/04923/2020).

\section{Availability of data and materials}

All data and materials in this article can be obtained by contacting the corresponding author, Henrique Oliveira (hjmo@|x.it.pt).

\section{Declarations}

\section{Ethics approval and consent}

This study was approved by the HECLHUBA on July 6th, 2014. The decision was published in the meeting minutes issued by the HECLHUBA board of directors, with the reference number of 2/2014. Written informed consent was obtained from all participants prior to the interviews. 


\section{Consent for publication}

Since the dignity, privacy and freedom of the participants were guaranteed according to the Helsinki Declaration, consent for the publication of the data in a scientific journal was granted.

\section{Competing interests}

The authors declare that they have no competing interests.

\section{Author details}

${ }^{1}$ School of Health, Polytechnic Institute of Beja, Beja, Portugal. ${ }^{2}$ Comprehensive Health Research Centre (CHRC), Universidade de Évora, Évora, Portugal. ${ }^{3}$ ISPA - Instituto Universitário de Ciências Psicológicas, Sociais e da Vida, Lisbon, Portugal. ${ }^{4}$ Instituto de Telecomunicações (IT), Lisbon, Portugal.

Received: 23 May 2020 Accepted: 29 April 2021

Published online: 17 May 2021

\section{References}

1. Kyu H, Abate D, Abate K, Abay S, et al. Global, regional, and national disability-adjusted life-years (DALYS) for 359 diseases and injuries and healthy life expectancy (HALE) for 195 countries and territories, 1990-2017: a systematic analysis for the Global Burden of Disease Study 2017. The Lancet. 2018;392:1859-922.

2. WHO. World health statistics. Monitoring health for the SDGs, sustainable development goals. Geneva: World Health Organization; 2020. p. 2020.

3. Raggi A, Corso B, Minicuci N, Quintas R, et al. Determinants of quality of life in ageing populations: results from a cross-sectional study in Finland Poland and Spain. PLoS ONE. 2016;11:e0159293.

4. Goes M, Lopes M, Oliveira H, Fonseca C, et al. A nursing care intervention model for elderly people to ascertain general profiles of functionality and self care needs. Sci Rep Nat Res. 2020;10:1-11.

5. Roser, M, Ritchie, H. Burden of disease. 2016. https://ourworldindata.org/ burden-of-disease. Accessed 25 Dec 2020.

6. Banham, D, Hawthorne, G, Goldney, R, Ratcliffe, J. Health-Related Quality of Life (HRQoL) changes in South Australia: comparison of burden of disease morbidity and survey-based health utility estimates. Health Qual Life Outcomes. 2014;12.

7. Health General Directorate. Health System Review - PORTUGAL (Final Report). PHS - Portuguese Health System; 2018.

8. Prince M, Wu F, Guo Y, Gutierrez-Robledo L, et al. The burden of disease in older people and implications for health policy and practice. Lancet. 2015;385:549-62.

9. Addington-Hall J, Kalra L. Measuring quality of life: Who should measure quality of life? BMJ. 2001;322:1417-20.

10. Goes, M, Lopes, M, Oliveira, H, Fonseca, C, et al. Biological and sociodemographic predictors of elderly quality of life living in the community in Baixo-Alentejo, Portugal. In: García-Alonso J, Fonseca C, editors. Gerontechnology. Communications in computer and information science, vol 1016. Springer, Cham; 2019. p. 319-26.

11. Porter M. What Is Value in Health Care? N Engl J Med. 2010;363:2477-81.

12. Cohn, A. Measuring quality of life. BMJ. 2016;354:i3816.

13. Bayliss E, Ellis J, Steiner J. Subjective assessments of comorbidity correlate with quality of life health outcomes: Initial validation of a comorbidity assessment instrument. Health Qual Life Outcomes. 2005;3:51.

14. Fleck, M. A avaliação da qualidade de vida - Guia para profissionais de saúde. Porto Alegre: Artmed Editora S.A.; 2008.

15. Van Leeuwen, K, Van Loon, M, Van Nes, F, Bosmans, J, et al. What does quality of life mean to older adults? A thematic synthesis. PLOS ONE. 2019;14:e0213263.

16. Pequeno, N, Cabral, N, Marchioni, D, Lima, S, et al. Quality of life assessment instruments for adults: a systematic review of population-based studies. Health and Quality of Life Outcomes. 2020;18.

17. Larson E, Sharma J, Bohren M, Tunçalp Ö. When the patient is the expert: measuring patient experience and satisfaction with care. Bull World Health Organ. 2019;97:563-9.

18. Ottati F, Campos M. Quality of life and coping strategies in the treatment of oncologic patients. Acta Colomb Psicol. 2014;17:103-11.
19. WHOQOL Group. Introducing the WHOQOL instruments. WHOQOL: measuring quality of life. 2020. https://www.who.int/tools/whoqol. Accessed December 25th, 2020.

20. WHOQOL Group. The structure of the WHOQOL-100. WHOQOL: measuring quality of life. 2020. https://www.who.int/tools/whogol/whoqol100. Accessed December 25th, 2020.

21. WHOQOL Group. Structure of the WHOQOL-BREF. WHOQOL: measuring quality of life. 2020. https://www.who.int/tools/whoqol/whogol-bref. Accessed December 25th, 2020.

22. Harper, A, Power, M, WHOQOL Group, X. Development of the World Health Organization WHOQOL-BREF quality of life assessment. The WHOQOL Group. Psychological medicine. 1998;28(3):551-8.

23. Skevington, S, Lotfy, M, O'Connell, K. The World Health Organization's WHOQOL-BREF quality of life assessment: Psychometric properties and results of the international field trial. A Report from the WHOQOL Group. Quality of Life Research. 2004;13:299-310.

24. Canavarro, M, Serra, A, Simões, M, Pereira, M, et al. WHOQOL-100 (Versão em Português de Portugal do Instrumento de Avaliação da Qualidade de Vida da Organização Mundial de Saúde). 2006. http:// www.fpce.uc.pt/saude/WHOQOL100.html. Accessed December 25th, 2020.

25. Canavarro, M, Serra, A, Simões, M, Pereira, M, et al. WHOQOL-BREF (Versão em Português de Portugal do Instrumento Abreviado de Avaliação da Qualidade de Vida da Organização Mundial de Saúde). 2006. http://www.fpce.uc.pt/saude/WHOQOL_Bref.html. Accessed December 25th, 2020.

26. Canavarro M, Serra A, Perreira M, Simões M, et al. WHOQOL disponíve para Portugal: Desenvolvimento dos Instrumentos de Avaliação da Qualidade de Vida da Organização Mundial de Saúde (WHOQOL-100 e WHOQOL-BREF). In: Canavarro M, Serra A, editors., et al., Qualidade de Vida e Saúde: Uma abordagem na perspectiva da Organização Mundial de Saúde. Lisboa: Fundação Calouste Gulbenkian; 2010. p. 171-90.

27. Souza A, Alexandre N, Guirardello E, Souza A. Psychometric properties in instruments evaluation of reliability and validity. Epidemiologia e Serviços de Saúde. 2017;26:649-59.

28. Keszei A, Novak M, Streiner D. Introduction to health measurement scales. J Psychosom Res. 2010;68:319-23.

29. Reeves, A, Baker, R, Casanova, M, Cheatham, S, et al. Examining the factorial validity of the Quality of Life Scale. Health and Quality of Life Outcomes. 2020;18.

30. Yin, S, Njai, R, Barker, L, Siegel, P, et al. Summarizing health-related quality of life (HRQOL): development and testing of a one-factor model. Population Health Metrics. 2016;14.

31. HECLHUBA. The LHUBA's health ethics committee (i.e. in Portuguese language: "Comissão de Ética para a Saúde da Unidade Local de Saúde do Baixo Alentejo"). 2020. http://www.ulsba.min-saude.pt/2019/02/28/ comissao-de-etica-para-a-saude/. Accessed 25 Dec 2020.

32. HECLHUBA. The health ethics committee of LHUBA is governed by an operating regulation, that was approved on September 17,2015 , by the Board of Directors. 2020. http://www.ulsba.min-saude.pt/wp-content/ uploads/sites/15/2019/02/Documento-Guia.pdf. Accessed 25 Dec 2020.

33. HECLHUBA. Helsinki declaration 2008 (Portuguese translation). 2020. http://www.ulsba.min-saude.pt/wp-content/uploads/sites/15/2019/02/ declaracaohelsinquia.pdf. Accessed 25 Dec 2020.

34. WIKI. Baixo Alentejo (intermunicipal community). 2020. https://en.wikip edia.org/wiki/Baixo_Alentejo_(intermunicipal_community). Accessed 25 Dec 2020.

35. LHUBA. Unidade Local de Saúde do Baixo Alentejo. 2020. http://www. ulsba.min-saude.pt/. Accessed 25 Dec 2020.

36. Scheaffer R, Mendenhall M, Ott R, Gerow K. Elementary survey sampling: cengage learning; 2012.

37. Oliveira A. Bioestatística descodificada, 2nd ed. Lisbon, Portugal: LIDEL; 2014.

38. Soper, D. Calculator: a-priori sample size for structural equation models. 2020. https://www.danielsoper.com/statcalc/calculator.aspx?id=89. Accessed 25 Dec 2020.

39. Westland J. Lower bounds on sample size in structural equation modeling. Electron Commer Res Appl. 2010;9:476-87.

40. Cohen, J. Statistical power analysis for the behavioral sciences. 2nd ed. Lawrence Erlbaum Associates Publishers; 1988. 
41. Westland J. Erratum to "Lower bounds on sample size in structural equation modeling. Electron Commerce Res Appl. 2010;9(6):476-87.

42. Rosseel Y. lavaan: an R package for structural equation modeling. J Stat Softw. 2012;48:1-36.

43. R Core Team. R: A language and environment for statistical computing. Vienna, Austria: R Foundation for Statistical Computing; 2020.

44. Rosseel Y. The Lavaan tutorial Ghent University (Belgium), Department of Data Analysis, 2020.

45. Li C-H. Confirmatory factor analysis with ordinal data: comparing robust maximum likelihood and diagonally weighted least squares. Behav Res Methods. 2016;48:936-49.
46. Marôco, J. Análise de equações estruturais: fundamentos teóricos, software and aplicações. 2nd ed. Pêro Pinheiro, Portugal: Report Number; 2014.

47. Timothy B. Confirmatory factor analysis for applied research. 2nd ed. New York: Guilford Press; 2015

\section{Publisher's Note}

Springer Nature remains neutral with regard to jurisdictional claims in published maps and institutional affiliations.
Ready to submit your research? Choose BMC and benefit from:

- fast, convenient online submission

- thorough peer review by experienced researchers in your field

- rapid publication on acceptance

- support for research data, including large and complex data types

- gold Open Access which fosters wider collaboration and increased citations

- maximum visibility for your research: over 100M website views per year

At BMC, research is always in progress.

Learn more biomedcentral.com/submissions 